\title{
Optimal treatment strategy in extremely elderly patients with hepatocellular carcinoma
}

\author{
A Ruzzenente*, S Pachera, C Iacono, A Valdegamberi, P Nicoli, \\ T Campagnaro, G Piccirillo and A Guglielmi
}

\begin{abstract}
Address: Department of Surgery and Gastroenterology, Division of Surgery A, University of Verona Medical School, Verona, Italy
\end{abstract}
* Corresponding author

from XXI Annual Meeting of The Italian Society of Geriatric Surgery

Terni, Italy. 4-6 December 2008

Published: I April 2009

BMC Geriatrics 2009, 9(Suppl I):AI8 doi:10.1/86/I47I-23I8-9-SI-AI8

This abstract is available from: http://www.biomedcentral.com/I47I-23I8/9/SI/AI8

(C) 2009 Ruzzenente et al; licensee BioMed Central Ltd.

\section{Background and objective}

The hepatocellular carcinoma (HCC) is a frequent cancer worldwide. This disease is more frequent in patients over 70 years and only few papers in literature analyze the clinical characteristics and the survival of elderly patients with HCC. The aim of this study is to describe the features and the results of treatment of patients older than 80 years with HCC.

\section{Methods}

464 patients with HCC observed from 1991 to 2007 were included into the study. All the patients were evaluated for treatment of HCC in relation to the severity of liver impairment and tumor stage. All the patients included into the study had no evidence of distant metastases. We compared the clinical characteristics and results in patients older or younger than 80 years.

\section{Results}

Of the 464 patients included into the study 414 were younger than 80 and 50 older than 80 years. Median follow up time for surviving patients was 25 months (range 1-155). 283 patients were in Child-Pugh class A, 161 in class B and 20 in class C. 271 patients had single HCC and 293 patients had multiple HCCs. 183 patients had HCC smaller than $3 \mathrm{~cm}, 121$ larger than $3 \mathrm{~cm}$ and smaller than $5 \mathrm{~cm}$ and 105 larger than $5 \mathrm{~cm}$. The severity of liver disease and the tumor stage was not significant different among patients younger or older than 80 years. $136(29.2 \%)$ patients were submitted to liver resection (LR), 232
(50.0\%) to local ablative therapies (LAT) (ethanol injection, radiofrequency ablation, chemoembolization), 8 $(1.7 \%)$ to liver transplantation (LT) and $88(19.0 \%)$ to supportive therapy (ST). Median survival time for all patients was 30.4 months (95\% CI 24-36). Overall survival was not significantly different in the group younger

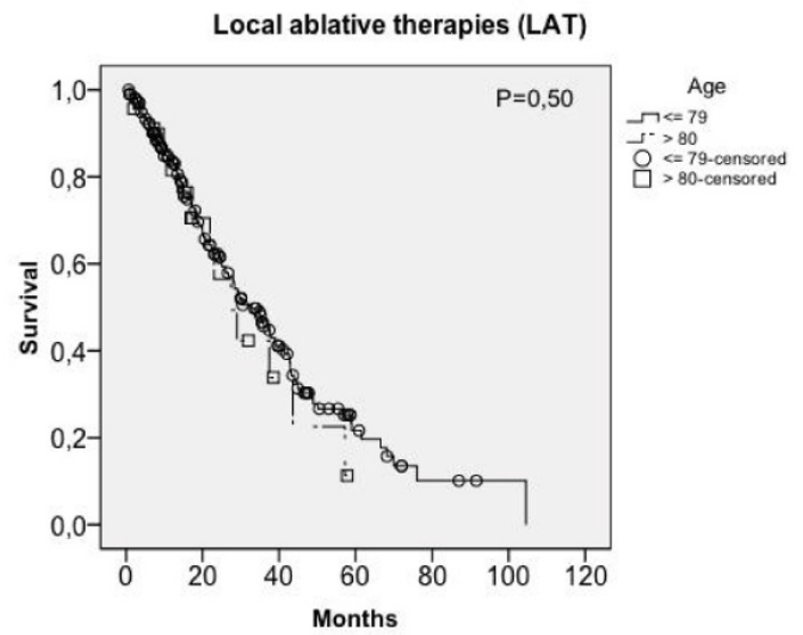

Figure I

Survival of patients with HCC after LAT according to different age group, survival is not significant different in patients younger or older than 80 years. 


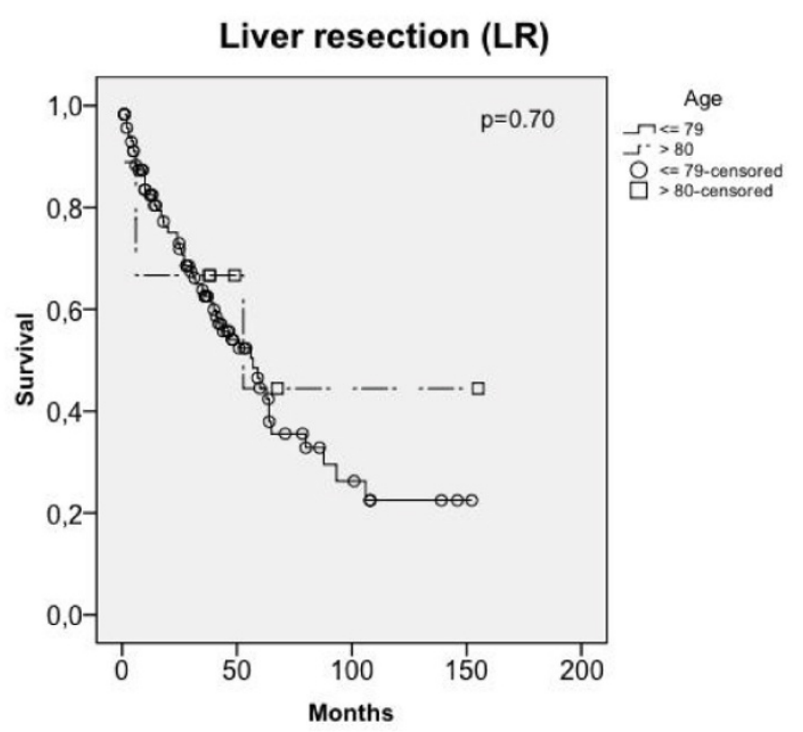

Figure 2

Survival of patients with HCC after LR according to different age group, survival is not significant different in patients younger or older than 80 years.

or older then 80 years with an actuarial 5-year survival of $27 \%$ and $25 \%$, respectively. Median survival time was 57 months for LR, 30 for LAT and 8 for ST, with a 5-year survival of $47 \%, 20 \%$ and $2.5 \%$ respectively $(p=0.001)$. In the LR, LAT and ST survival was not significantly different if the two group of patients, younger and older than 80 years (Figures 1,2).

\section{Conclusion}

The present study shows that LR and LAT for patients with HCC older than 80 years can achieve good results that are comparable to younger patients. Advanced age should not be considered a contraindication for LAT or LR of HCC; optimal treatment strategy should not be guided by patients' age but by the tumor stage and the degree of liver dysfunction.
Publish with Biomed Central and every scientist can read your work free of charge

"BioMed Central will be the most significant development for disseminating the results of biomedical research in our lifetime. " Sir Paul Nurse, Cancer Research UK

Your research papers will be:

- available free of charge to the entire biomedical community

- peer reviewed and published immediately upon acceptance

- cited in PubMed and archived on PubMed Central

- yours - you keep the copyright

Submit your manuscript here:

http://www.biomedcentral.com/info/publishing_adv.asp 